\title{
ANALYSIS OF THE CRACK PROPAGATION IN FIBER- REINFORCED CONCRETE SPECIMENS USING THE BEM
}

\author{
GABRIELA M. S. BRISOLA ${ }^{1}$, LEANDRO PALERMO JR. ${ }^{2} \&$ LUIZ C. ALMEIDA $^{2}$ \\ ${ }^{1}$ FACENS - Sorocaba Engineering College, Sorocaba, Brazil \\ ${ }^{2}$ School Civ. Eng. Arch. Urban Design, University of Campinas, Brazil
}

\begin{abstract}
The mechanical properties of plain concretes are improved with the introduction of steel fibers like the material toughness along with limited crack widths. Numerical investigations on fiber reinforced concrete specimens use models for cohesive crack propagation in quasi-brittle materials. The present crack propagation analysis considered the single-edge notched beam under the three-point bending test. The material softening modeling used the cohesive law with two straight lines within a pure mode I for the crack growth. The dual boundary element method employed quadratic elements and the tangential differential operator in the traction boundary integral equation. The introduction of the constitutive law in the system of equations allowed the direct computation of the cohesive forces at each incremental loading step. The boundary element mesh employed continuous elements along the crack surface and the results obtained are compared with those available in the literature.

Keywords: crack analysis, cohesive model, fiber reinforced concrete, dual boundary element model, tangential differential operator.
\end{abstract}

\section{INTRODUCTION}

The improvement of the mechanical properties in plain concrete due to the introduction of steel fibers has motivated the increase of structural applications using this solution. Furthermore, the combination of different types of fibers has extended the range of the applications with fiber reinforced concrete beyond the massive elements. The subsequent researches along the years have demonstrated the fictitious crack model is efficient to describe the tensile behavior of fiber-reinforced concrete (FRC) in the numerical implementations [1]-[3]. The stress concentration in front of the notch tip in concrete specimens with an initial crack develops the damage zone with micro-cracks. In spite of the crack surfaces are not completely separated in this region, the partly destroyed material is still able to transfer stress across the crack trace behind the fictitious crack tip, which is called the fictitious crack or the cohesive zone, as shown in Fig. 1. The fictitious crack model considers the linear elastic behavior before the crack initiation and the stresses along the cohesive zone are taken to be a function of the crack opening. The linear function was employed in the beginning for the relation stress-crack opening to describe the softening in plain concrete specimens within a pure mode I for the crack growth. Peterson was the first to suggest using the function with two straight lines [4] for analysis using plain concrete specimens. Nevertheless, the relation for stress-crack opening function representing the tensile behavior of FRC requires at least a function using two straight lines. The bending failure in concrete beams can be modeled with the development of the fictitious crack in an elastic layer with the thickness proportional to the beam depth [5]. An assessment of the flexural strengths of fiber-reinforced composites and the influence of the fiber bridging on the overall structural behavior were studied in [6], [7], Sousa and Gettu [8], and Slowik et al. [9] determined piecewise linear cohesive models for FRC by minimizing the difference between numerical simulation and experimental test results. 


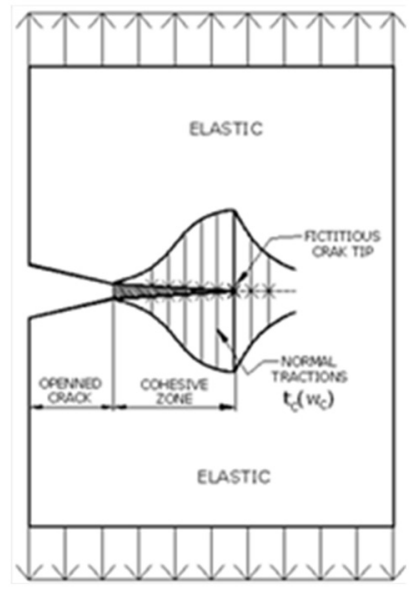

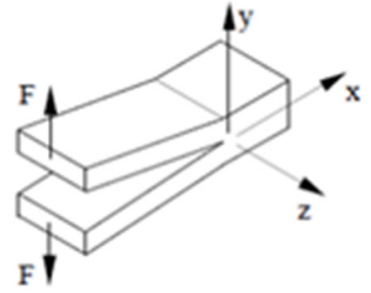

Mode I

Figure 1: Crack in cohesive material: Stress distribution and fracture mode I.

Several numerical methods besides the FEM have been used to perform crack analyses. The dual boundary element method (DBEM) is one of the most widely used due to its accuracy in computation of the stress intensity factors and the simplicity of adding more elements for crack propagation [10]. The crack analyses for cohesive materials were studied with the DBEM by Saleh and Aliabadi [11], [12], with the Galerkin multizone BEM by Chen et al. [13] and with the displacement discontinuity BEM by Gospodinov [14]. Karlis et al. employed the two dimensional gradient elasticity for crack analyses with the BEM in [15], and Leonel and Venturini used the tangent operator in the non-linear analyses with the BEM for crack propagation in quasi-brittle materials in [16]. Tavara et al. performed a BEM analysis of crack propagation along the fiber-matrix interface of laminates using a linear elastic-brittle interface model in [17]. Trinh et al. employed the fast multipole symmetric Galerkin BEM to solve multizone and multicrack problems in [18], and Benedetti and Aliabadi employed the BEM in multiscale modeling for polycrystalline materials to analyze material degradation and fracture in [19].

The DBEM is adopted here with the strong singularity of the traction boundary integral equation (BIE) reduced with the tangential differential operator (TDO). The TDO, in conjunction with integration by parts, is a technique to reduce the order of singularity in the integrand kernels of BIEs using Kelvin-type fundamental solutions, which is usually referred as the hypersingular kernel. The TDO was first used by Kupradze [20], and by Sladek and Sladek [21] in the solution for a curved crack. Regularized formulations with TDO for gradients in potential problems, and in stress BIEs for elasticity problems were shown by Bonnet in [22]. The non-conformal interpolations require an additional care in the numerical implementations for the TDO, as explained to the traction BIEs of elasticity for two- and three-dimensional problems in [23], [24], and in the BIE for stresses of the plate bending using Reissner and Mindlin models [25].

\section{DUAL BOUNDARY INTEGRAL EQUATIONS FOR COHESIVE MATERIALS}

A single domain is considered in the solution of general mixed-mode crack problems with the DBEM. The displacement and traction BIEs are used and respectively applied in each one of the crack surfaces. Although the integration path is still the same for coincident points 
on crack surfaces, the respective boundary integral equations are distinct. The collocation point needed to perform the traction BIE and the strategy used to treat improper integrals are the key features of this formulation. The displacement and traction BIEs for the DBEM are next written:

$$
\begin{gathered}
\frac{1}{2} u_{i}\left(x^{\prime}\right)+\int_{\Gamma} T_{i j}\left(x^{\prime}, x\right) u_{j}(x) d \Gamma(x)=\int_{\Gamma} U_{i j}\left(x^{\prime}, x\right) t_{j}(x) d \Gamma(x), \\
\left.\frac{1}{2} t_{k}\left(x^{\prime}\right)=n_{a}\left(x^{\prime}\right) \mid C_{a k i m} \int_{\Gamma} \sigma_{i b j}\left(x^{\prime}, x\right) D_{m b}\left[u_{j}(x)\right] d \Gamma(x)-\int_{\Gamma} \sigma_{j a k}\left(x^{\prime}, x\right) t_{j}(x) d \Gamma(x)\right],
\end{gathered}
$$

with

$$
\begin{gathered}
C_{a k i m}=\mu\left(\frac{2 v}{1-2 v} \delta_{a k} \delta_{i m}+\delta_{a i} \delta_{k m}+\delta_{a m} \delta_{k i}\right), \\
D_{b m}[f(x)]=n_{b}(x) f_{, m}(x)-n_{m}(x) f_{, b}(x),
\end{gathered}
$$

where $\mathrm{U}_{\mathrm{ij}}\left(\mathrm{x}^{\prime}, \mathrm{x}\right)$ and $\mathrm{T}_{\mathrm{ij}}\left(\mathrm{x}^{\prime}, \mathrm{x}\right)$ are the displacement and traction, respectively, in the direction $\mathrm{j}$ at boundary point $\mathrm{x}$ due to a singular load in the direction $\mathrm{i}$ at the collocation point $\mathrm{x}^{\prime}$ based on the Kelvin solution for two-dimensional problems, $\mathrm{u}_{\mathrm{i}}(\mathrm{x})$ and $\mathrm{t}_{\mathrm{i}}(\mathrm{x})$ are the displacement and traction at boundary point $\mathrm{x}$, respectively, $\mathrm{n}_{\mathrm{a}}\left(\mathrm{x}^{\prime}\right)$ is the direction cosine of the outward normal at collocation point $x^{\prime}$. $C_{a k i m}$ is the Hooke tensor for an isotropic material, $\sigma_{i b j}$ is the stress $\sigma_{b j}$ at boundary point $x$ due to a singular load in the direction $i$ at collocation point $x^{\prime}, \mu$ is the shear modulus, $v$ is the Poisson ratio, $\delta_{\mathrm{ij}}$ is the Kronecker delta and $\mathrm{D}_{\mathrm{bm}}()$ is the tangential operator.

The displacement BIE, eqn (1), has a $1 / \mathrm{r}$ singularity and a logarithmic singularity in the integrand kernels at the right and left members, respectively, when the field point approaches the collocation point. The introduction of TDO in the first integral of the right member of the traction BIE, eqn (2), reduced the strong singularity and $1 / \mathrm{r}$ singularities result in both integrand kernels. The continuity requirements should be satisfied at the positions of the collocation points for both BIEs. Positions in the interior of the boundary element satisfy the continuity requirements for both BIEs whereas positions at the ends of continuous elements can only be used for the displacement BIE.

The surfaces of the crack region are connected by the cohesive material in the cohesive zone (Fig. 1). Subsequent loadings increase the separation between these points and eventually lead to cracking. The stress-crack opening curve for the cohesive zone to represent the characteristics of the tensile behavior of FRC uses the function with two straight lines in this study. This function is shown in Fig. 2, where $f_{t}$ is the tensile strength, and $w_{c}$ is the maximum widening of the fracture zone when it is still able to transfer stress. The breaking point value is defined in terms of the opening value $\left(\mathrm{w}_{1}\right)$ at the corresponding value for the tensile strength $\left(f_{1}\right)$ of the normal traction:

$$
\sigma(w)=\left\{\begin{array}{c}
0 \leq w \leq w_{1} \Rightarrow \sigma(w)=f_{t}\left(1-\frac{w}{w_{c}^{\prime}}\right), \\
w_{1} \leq w \leq w_{c} \Rightarrow \sigma(w)=f_{t}^{\prime}\left(1-\frac{w}{w_{c}}\right), \\
w>w_{c} \Rightarrow \sigma(w)=0 .
\end{array}\right.
$$

A finite domain with the boundary line $\Gamma_{\mathrm{e}}$ and containing a crack with the cohesive zone is shown in Fig. 3. The region without the cohesive material is represented by $\Gamma_{1}$ and $\Gamma_{4}$ on 


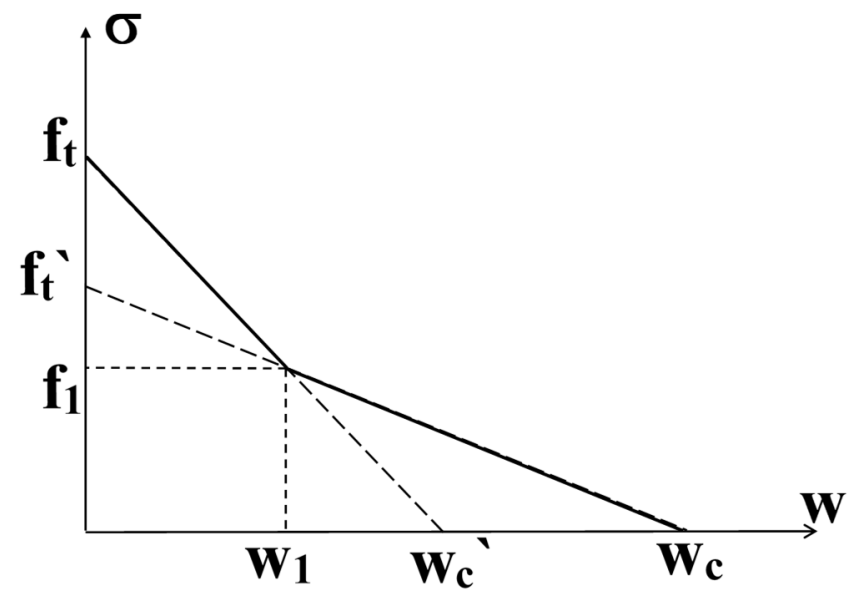

Figure 2: Stress-crack opening function using with two straight lines.

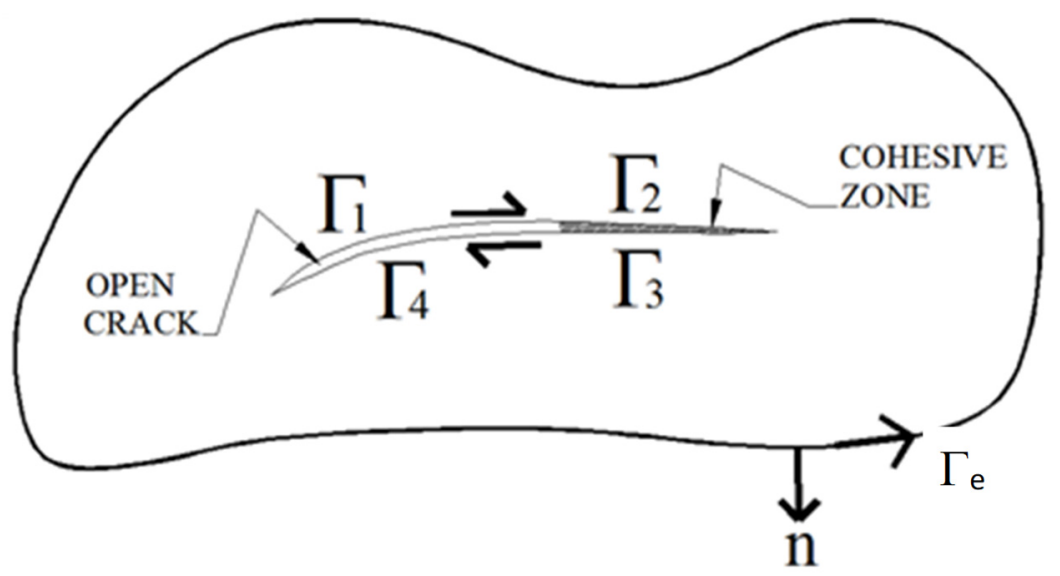

Figure 3: Finite domain containing a crack.

each crack surface whereas $\Gamma_{2}$ and $\Gamma_{3}$ are on each crack surface of the region containing cohesive material (cohesive zone). The normal tractions in the cohesive zone connect the crack surfaces and have opposite signs with equal magnitude, i.e. $\mathrm{t}^{3}$ on the crack surface $\Gamma_{3}$ is equal to $-t^{2}$ on the crack surface $\Gamma_{2}$. This condition is used to simplify the equations of DBEM for this problem.

$$
\begin{gathered}
\frac{1}{2} u_{i}\left(x^{\prime}\right)+\int_{\Gamma} T_{i j}\left(x^{\prime}, x\right) u_{j}(x) d \Gamma(x)=\int_{\Gamma_{e}} U_{i j}\left(x^{\prime}, x\right) t_{j}(x) d \Gamma(x) \\
+\int_{\Gamma_{2}} U_{i j}\left(x^{\prime}, x\right) t_{j}^{2}(x) d \Gamma(x)-\int_{\Gamma_{3}} U_{i j}\left(x^{\prime}, x\right) t_{j}^{2}(x) d \Gamma(x),
\end{gathered}
$$




$$
\begin{gathered}
\frac{1}{2} t_{k}\left(x^{\prime}\right)=n_{a}\left(x^{\prime}\right)\left\lfloor C_{a k i m} \int_{\Gamma} \sigma_{i b j}\left(x^{\prime}, x\right) D_{m b}\left[u_{j}(x)\right] d \Gamma(x)-\int_{\Gamma_{e}} \sigma_{j a k}\left(x^{\prime}, x\right) t_{j}(x) d \Gamma(x)\right\rfloor \\
-n_{a}\left(x^{\prime}\right) \int_{\Gamma_{2}} \sigma_{j a k}\left(x^{\prime}, x\right) t_{j}^{2}(x) d \Gamma(x)+n_{a}\left(x^{\prime}\right) \int_{\Gamma_{3}} \sigma_{j a k}\left(x^{\prime}, x\right) t_{j}^{2}(x) d \Gamma(x) .
\end{gathered}
$$

The traction in the direction $\mathrm{j}$ on the crack surface $\Gamma_{2}$ within the cohesive zone $\left(\mathrm{t}^{2}\right)$ appeared in both integrals performed on crack surfaces $\Gamma_{2}$ and $\Gamma_{3}$ in eqns (4) and (5) because the traction $t^{3}$ is equal to $-t^{2}{ }_{j}$ in the cohesive zone. The numerical implementation in the present study employed eqns (4) and (5), which is different to the formulation used in [26], [27].

The crack propagation is directly related to the maximum principal stress, which has to be always normal to the crack surfaces, and the extension is such that the maximum principal stress at the new tip position is equal to the critical $f_{t}$ value during continued loading. The beam in the three-point bending test is considered as a generalized plane stress problem and the maximum principal stress is obtained according to following expression:

$$
\sigma_{\text {max }}=\frac{1}{2}\left(\sigma_{n}+\sigma_{t}+\sqrt{\left(\sigma_{n}-\sigma_{t}\right)^{2}+4 \tau_{n t}^{2}}\right) .
$$

\section{NUMERICAL IMPLEMENTATION}

The system of equations obtained from eqns (4) and (5) is given next with the unknown values including the tractions in the cohesive zone $\left(\mathrm{t}^{2}\right)$. The additional equation in the system of equation required to the solution corresponds to the cohesive law. The tractions in the cohesive zone are directly obtained at each incremental loading step with this strategy:

$$
\left[\begin{array}{cccc}
H_{e e} & H_{e o} & H_{e z} & -G_{e 2} \\
H_{o e} & H_{o o} & H_{o z} & -G_{o 2} \\
H_{z e} & H_{z o} & H_{z z} & -G_{z 2} \\
0 & 0 & A & B
\end{array}\right]\left\{\begin{array}{l}
u^{e} \\
u^{o} \\
u^{z} \\
t^{2}
\end{array}\right\}=\left[\begin{array}{cc}
G_{e e} & 0 \\
G_{o e} & 0 \\
G_{z e} & 0 \\
0 & C
\end{array}\right]\left\{\begin{array}{c}
t^{e} \\
w_{f}
\end{array}\right\} .
$$

Eqn (7) summarizes the system of equations where the dual eqns (4) and (5) are converted to submatrices $\mathrm{H}_{\mathrm{ij}}$ and $\mathrm{G}_{\mathrm{ij}}$, and the cohesive law is converted to submatrices $\mathrm{A}, \mathrm{B}$ and $\mathrm{C}$. The indices $\mathrm{e}, \mathrm{o}$ and $\mathrm{z}$ are related to the boundary portions and correspond to the external boundary, the open crack boundary and the cohesive zone, respectively. Submatrices A and $\mathrm{B}$ relate the displacements and tractions in the normal and tangent directions, respectively, on the crack surfaces in the cohesive zone according to the constitutive law. The numerical algorithm is summarized next, considering the boundary portions shown in Fig. 3 and the constitutive law shown in Fig. 2:

a) Phase $1, t^{2}<f_{t}$. The traction in the normal direction is less the tensile strength $\left(f_{t}\right)$, the crack surfaces remain jointed, and without relative displacements. Submatrices B and C are zero, whereas submatrix A contains direction cosines relating the displacements in the directions $\mathrm{x}_{\mathrm{i}}$, i.e., the openings in the normal and tangent directions are zero:

$$
\begin{aligned}
& u_{i}^{2} n_{i}^{2}+u_{i}^{3} n_{i}^{3}=0, \\
& u_{i}^{2} s_{i}^{2}+u_{i}^{3} s_{i}^{3}=0 .
\end{aligned}
$$

b) Phase $2, t^{2}=f_{t}$. The traction in the normal direction reaches $f_{t}$ and openings will appear in the cohesive zone for subsequent loads. The cohesive law is introduced in lines of submatrices $\mathrm{B}$ and $\mathrm{C}$ to relate openings and tractions in the normal direction. The eqn (8) is modified with the first equation of the constitutive law. No tractions appear in the 
tangent direction, i.e. the eqn (9) is replaced by the condition of tractions in the tangent direction equal to zero. The following equations replaces eqns (8) and (9), respectively:

$$
\begin{gathered}
\left(u_{i}^{2} n_{i}^{2}+u_{i}^{3} n_{i}^{3}\right)-\frac{w_{c}^{\prime}}{f_{t}} n_{i}^{2} t_{i}^{2}=-w_{c}^{\prime}, \\
s_{i}^{2} t_{i}^{2}=0 .
\end{gathered}
$$

c) Phase $3, t^{2}=f_{1}$. The breaking point is reached when the traction in the normal direction is equal to $f_{1}$. Further openings in the cohesive zone due to subsequent loads will be according to the second equation of the constitutive law show in eqn (3). The condition for tractions in the tangent direction remains unchanged. The following equation replaces eqn (10):

$$
\left(u_{i}^{2} n_{i}^{2}+u_{i}^{3} n_{i}^{3}\right)-\frac{w_{c}}{f_{t}^{\prime}} n_{i}^{2} t_{i}^{2}=-w_{c} .
$$

d) No tractions appear in in the cohesive zone when the critical opening $\left(\mathrm{w}_{\mathrm{c}}\right)$ is reached. It means that the tractions $\left(\mathrm{t}^{2}\right)$ at that point on the crack surfaces must be eliminated from the system of equations. Eqns (11) and (12) in the corresponding lines of matrices A and $\mathrm{B}$ are replaced by:

$$
\begin{aligned}
& t_{1}^{2}=0, \\
& t_{2}^{2}=0 .
\end{aligned}
$$

There was built a boundary element code using quadratic boundary elements and based in eqns (4) and (5). Quadratic shape functions were employed for the isoparametric boundary elements, with collocation points always placed on the boundary. The same mapping function was used for conformal and non-conformal interpolations, i.e., nodes at the ends of the quadratic elements remained at the ends when discontinuous elements were employed. The collocation points for the displacement BIE were positioned at element nodes in conformal interpolations $\left(\xi^{\prime}=-1\right.$ and $\left.\xi^{\prime}=0\right)$ and shifted to the interior of boundary elements in the case of non-conformal interpolations $\left(\xi^{\prime}= \pm 0.67\right.$, and $\left.\xi^{\prime}=0\right)$. In contrast, to satisfy the continuity requirements for the traction BIE, collocation points for the traction BIE were always positioned inside boundary elements for both interpolation types, i.e. $\left(\xi^{\prime}= \pm 0.67\right)$ for conformal interpolations and $\left(\xi^{\prime}= \pm 0.67\right.$, and $\left.\xi^{\prime}=0\right)$ for non-conformal interpolation. This strategy for the positions of collocation points in the DBEM was discussed in [28]. The singularity subtraction [29] and the transformation of variable technique [30] were employed for the Cauchy and weak-type singularity, respectively, when integrations were performed on elements containing the collocation points. The standard Gauss-Legendre scheme was employed for integrations on elements not containing the collocation points.

\section{NUMERICAL RESULTS}

Experimental and numerical analyses for plain concrete were performed in [4] using the notched beam under the three-point bending test shown in Fig. 4. This case was studied in [27] and it is repeated here because the formulation and the computer code were changed. The depth of the beam (d) is $0.2 \mathrm{~m}$, the width is $0.05 \mathrm{~m}$, and the length (l) is $2.0 \mathrm{~m}$. The adopted ratio between notched depth and beam depth $(\mathrm{a} / \mathrm{d})$ was 0.5 . The Poisson's ratio $(\mathrm{v})$ was 0.2 and the Table 1 presents the properties used in the analysis of the crack propagation. Peterson [4] presented results for crack propagation obtained experimentally for two values 


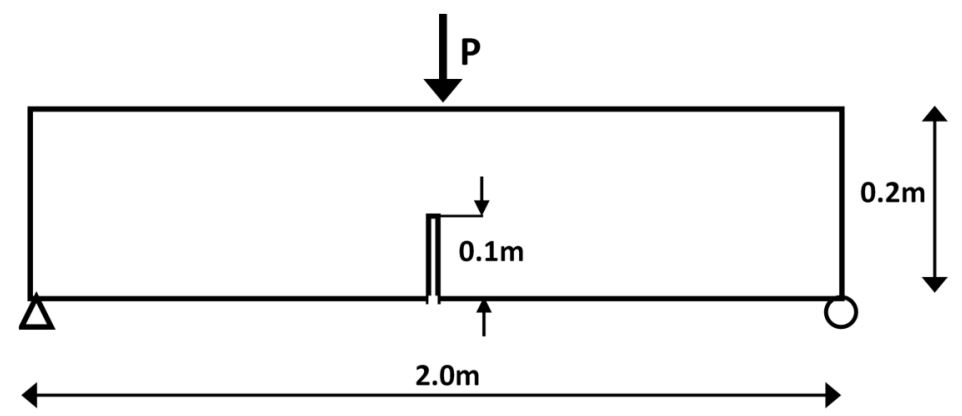

Figure 4: The notched beam subjected to the three-point bending test in [4].

Table 1: Mechanical properties according to the constitutive laws in [4].

\begin{tabular}{|l|c|c|c|c|c|c|}
\hline$\sigma$-w curve & $\begin{array}{c}\mathrm{G}_{\mathrm{f}} \\
\left(\mathrm{Nm}^{-1}\right)\end{array}$ & $\begin{array}{c}\mathrm{f}_{\mathrm{t}} \\
(\mathrm{MPa})\end{array}$ & $\begin{array}{c}\mathrm{f}_{1} \\
(\mathrm{MPa})\end{array}$ & $\begin{array}{c}\mathrm{W}_{\mathrm{c}} \\
(\mathrm{mm})\end{array}$ & $\begin{array}{c}\mathrm{w}_{1} \\
(\mathrm{~mm})\end{array}$ & $\begin{array}{c}\mathrm{E}_{\mathrm{c}} \\
(\mathrm{MPa}\end{array}$ \\
\hline One straight line (SL) & 124 & 3.33 & - & 0.07450 & - & 30,000 \\
\hline Two straight lines $(\mathrm{C})$ & 124 & 3.33 & 1.11 & 0.13400 & 0.02979 & 30,000 \\
\hline
\end{tabular}

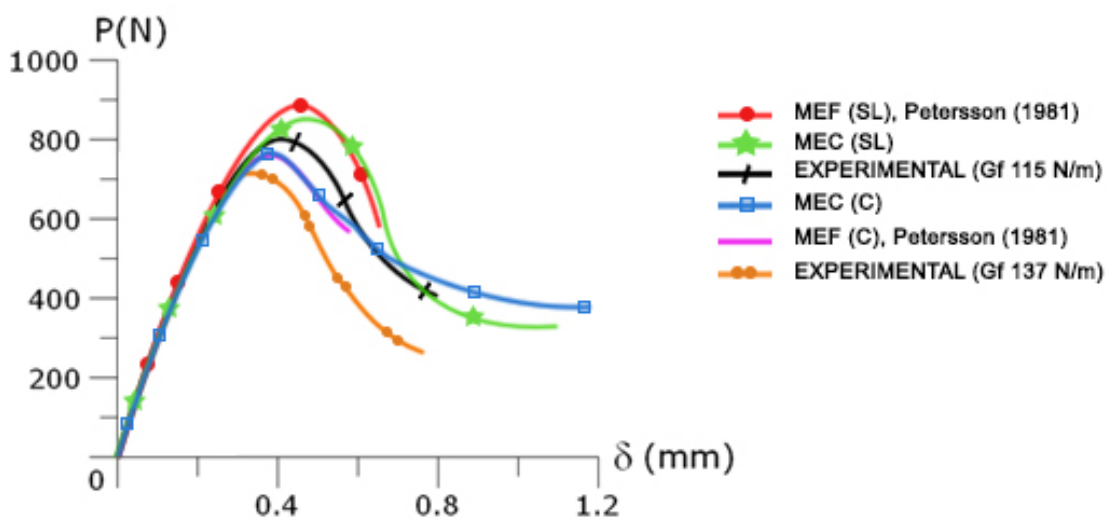

Figure 5: Comparison between the results obtained and those in [4] by Peterson.

of fracture energy $\left(\mathrm{G}_{\mathrm{f}}\right): 115 \mathrm{Nm}^{-1}$ and $137 \mathrm{Nm}^{-1}$. Experimental results were compared [4] with those obtained from a numerical analysis with the FEM using $124 \mathrm{Nm}^{-1}$ for $\mathrm{G}_{\mathrm{f}}$, which was the median value of the fracture energy values of the experiments. Two constitutive laws were considered in the numerical analyses [4]: a) Straight line and b) Two straight lines.

The comparison between the experimental and numerical results presented in [4] with those obtained with the present formulation is shown in Fig. 5. There were included results obtained with the present formulation when one straight line was used because the code built for the constitutive law with two straight lines can be simplified to that with one straight line. The results obtained matched those obtained by Peterson [4] and the behavior of the present formulation was stable in the post-peak softening, as shown by the blue and green lines in Fig. 5. 
The results obtained in analyses with FRC are compared with those presented in [31]. Fig. 6 presents the specimens used in [31], which the aspect ratio is different to that in Fig 4. The depth of the beam (d) is $125 \mathrm{~mm}$, the width (b) is $80 \mathrm{~mm}$, the ratio between notched depth and beam depth $(\mathrm{a} / \mathrm{d})$ is 0.3333 , and the Poisson's ratio $(\mathrm{v})$ is 0.2 . Table 2 presents the properties used in [31].

At the end of the crack propagation, there were employed 122 quadratic boundary elements ( 231 boundary nodes) with two boundary nodes placed at each corner and at the fictitious crack tip. The relative values of the peak load and the deflection were considered in Fig. 7 to show the difference between values obtained with SFRC specimens to that with plain concrete. The similar pre-peak behavior with respect to the plain concrete is shown in Fig. 7 whereas the comparison of the post-peak softening points out to the higher ductility for the fiber-reinforced specimens. The peak values for loads as well as the limit load after the softening are similar to those presented in [31].

\section{CONCLUSIONS}

The results obtained in the crack propagation analyses with the present DBEM formulation matched those in the literature. The meshes on the crack surfaces employed continuous quadratic boundary elements. The present code is different to that used in [26], [27], which employed linear boundary elements and considered different DBEM equations. Furthermore, the formulation using eqns (4) and (5) was stable when the constitutive law employed two straight lines with reference to that presented in [27] without reducing or changing benefits on the direct computation of the cohesive forces at each incremental loading step.

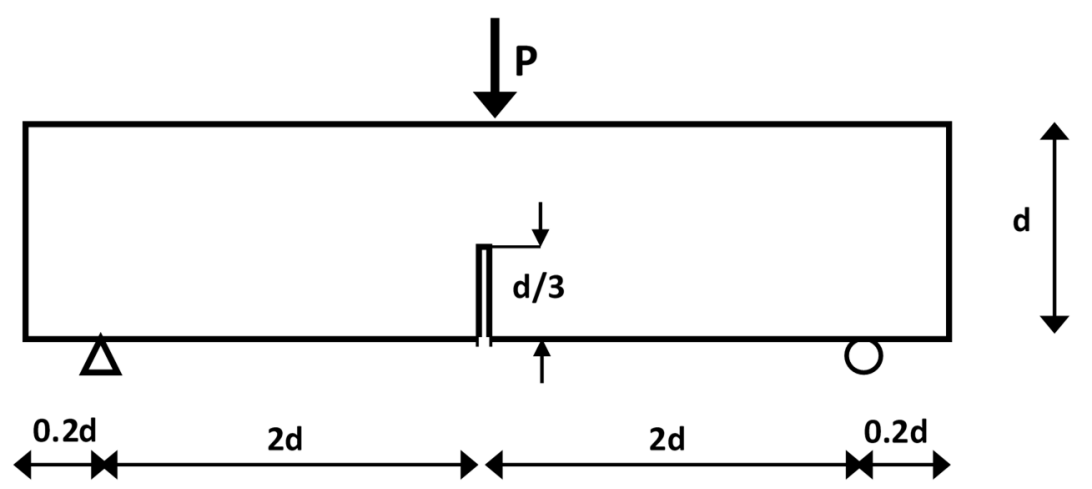

Figure 6: The notched beam subjected to the three-point bending test in [31].

Table 2: Mechanical properties used in [31].

\begin{tabular}{|l|c|c|c|c|c|c|}
\hline$\sigma$-w curve & $\begin{array}{c}\mathrm{G}_{\mathrm{f}} \\
\left(\mathrm{Nm}^{-1}\right)\end{array}$ & $\begin{array}{c}\mathrm{f}_{\mathrm{t}} \\
(\mathrm{MPa})\end{array}$ & $\begin{array}{c}\mathrm{f}_{1} \\
(\mathrm{MPa})\end{array}$ & $\begin{array}{c}\mathrm{W}_{\mathrm{c}} \\
(\mathrm{mm})\end{array}$ & $\begin{array}{c}\mathrm{W}_{1} \\
(\mathrm{~mm})\end{array}$ & $\begin{array}{c}\mathrm{E}_{\mathrm{c}} \\
(\mathrm{MPa}\end{array}$ \\
\hline Plain concrete & 72 & 2.81 & 0.55 & 0.18 & 0.016 & 25,127 \\
\hline SFRC -1 & 3,160 & 2.77 & 0.9 & 6.9 & 0.04 & 36,162 \\
\hline SFRC -2 & 3,878 & 2.77 & 1.52 & 5.03 & 0.04 & 36,162 \\
\hline Micro - FRC & 730 & 2.81 & 0.47 & 3.0 & 0.0175 & 25,127 \\
\hline Macro - FRC & 22,520 & 2.81 & 0.9 & 50.0 & 0.014 & 25,127 \\
\hline
\end{tabular}




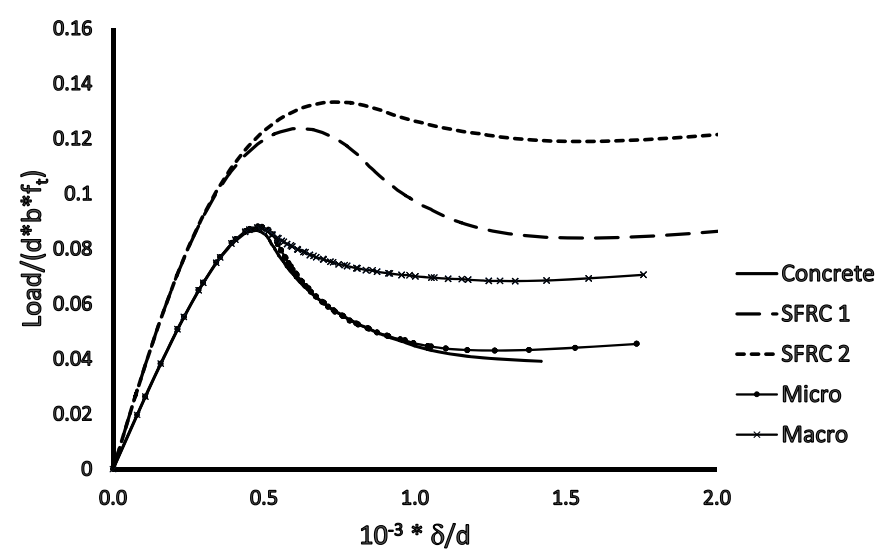

Figure 7: Results obtained using mechanical properties from Table 2 [31].

\section{REFERENCES}

[1] Hillerborg, A., Modeer, M. \& Petersson, P.E., Analysis of crack formation and crack growth in concrete by means of fracture mechanics and finite elements. Cement and Concrete Research, 6(6), pp. 773-781, 1976. DOI: 10.1016/0008-8846(76)90007-7.

[2] Hillerborg, A., Analysis of fracture by means of the fictitious crack model, particularly for fiber-reinforced concrete. International Journal of Cement Composites, 2(4), pp. 177-184, 1980.

[3] Carpinteri, A., Post-peak and post-bifurcation analysis of cohesive crack propagation. Engineering Fracture Mechanics, 32(2), pp. 265-278, 1989. DOI: 10.1016/00137944(89)90299-3.

[4] Peterson, P.E., Crack Growth and Development of Fracture Zone in Plain Concrete and similar materials, Report $N^{o}$ TVBM-1006, Division of Building Materials, Lund Institute of Technology: Lund Sweden, 1981.

[5] Olesen, J.F., Fictitious crack propagation in fiber-reinforced concrete beams. Journal of Engineering Mechanics, 127(3), pp. 272-280, 2001. DOI: 10.1061/(asce)07339399(2001)127:3(272).

[6] Maalej, M. \& Li, V.C., Flexural Strength of fiber cementitious composites. Journal of Materials in Civil Engineering, 6(3), pp. 390-406, 1994.

[7] Li, V.C., Lin, Z. \& Matsumoto, T., Influence of fiber bridging on structural size-effect. International Journal of Solids and Structures, 35(31-32), pp. 4223-4238, 1998. DOI: 10.1016/s0020-7683(97)00311-9.

[8] Sousa, J.L.A.O. \& Gettu, R., Determining the tensile stress-crack opening curve of concrete by inverse analysis. Journal of Engineering Mechanics, 132(2), pp. 141-148, 2006. DOI: 10.1061/(asce)0733-9399(2006)132:2(141).

[9] Slowik, V., Villmann, B., Bretschneider, N. \& Villmann, T., Computational aspects of inverse analyses for determining softening curves of concrete. Computer Methods in Applied Mechanics and Engineering, 195(52), pp. 7223-7236, 2006.

DOI: 10.1016/j.cma.2005.04.021.

[10] Brebbia, C.A., The birth of the boundary element method from conception to application. Engineering Analysis with Boundary Elements, 77, pp. iii-x, 2017. DOI: 10.1016/j.enganabound.2016.12.001. 
[11] Saleh, A.L. \& Aliabadi, M.H., Crack growth analysis in concrete using boundary element method. Engineering Fracture Mechanics, 51(4), pp. 533-545, 1995. DOI: 10.1016/0013-7944(94)00301-w.

[12] Saleh, A.L. \& Aliabadi, M.H., Fracture mechanics analysis of crack on plain concrete using the boundary element methods. Engineering Fracture Mechanics, 69(2), pp. 267-280, 2002. DOI: 10.1016/s0013-7944(01)00089-3.

[13] Chen, T., Wang, B., Cen, Z. \& Wu, Z., A symmetric Galerkin multi-zone boundary elemento method for cohesive crack growth. Engineering Fracture Mechanics, 63(5), pp. 591-609, 1999. DOI: 10.1016/s0013-7944(99)00036-3.

[14] Gospodinov, G., Boundary element modelling of cohesive cracks using displacement discontinuity method. Advances in Boundary Element Techniques, pp. 19-26, 2003.

[15] Karlis, G.F., Tsinopoulos, S.V., Polyzos, D. \& Beskos, D.E., Boundary Element analysis of mode I and mixed mode (I and II) crack problems of 2-D gradient elasticity. Computer Methods in Applied Mechanics and Engineering, 196(49-52), pp. 50925103, 2007. DOI: 10.1016/j.cma.2007.07.006.

[16] Leonel, E.D. \& Venturini, W.S., Non-linear boundary element formulation with tangent operator to analyze crack propagation in quasi-brittle materials. Engineering Analysis with Boundary Elements, 34(2), pp. 122-129, 2010.

DOI: 10.1016/j.enganabound.2009.08.005.

[17] Távara, L., Mantic, V., Graciani, E. \& París, F., BEM analysis of crack onset and propagation along fiber-matrix interface under transverse tension using a linear elastic-brittle interface model. Engineering Analysis with Boundary Elements, 35(2), pp. 207-222, 2011. DOI: 10.1016/j.enganabound.2010.08.006.

[18] Trinh, Q.T., Mouhoubi, S., Chazallon, C. \& Bonnet, M., Solving multizone and multicrack elastostatic problems: A fast multipole symmetric Galerkin boundary element method approach. Engineering Analysis with Boundary Elements, 50, pp. 486-495, 2015. DOI: 10.1016/j.enganabound.2014.10.004.

[19] Benedetti, I. \& Aliabad, M.H., Multiscale modeling of polycrystalline materials: A boundary element approach to material degradation and fracture. Computer Methods in Applied Mechanics and Engineering, 289, pp. 429-453, 2015.

DOI: 10.1016/j.cma.2015.02.018.

[20] Kupradze, V.D., Three-Dimensional Problems of the Mathematical Theory of Elasticity and Thermoelasticity, North Holland, 1979.

[21] Sladek, J. \& Sladek, V., Three-dimensional curved crack in an elastic body. International Journal of Solids and Structures, 19(5), pp. 425-436, 1983. DOI: 10.1016/0020-7683(83)90053-7.

[22] Bonnet, M., Boundary Integral Equation Methods for Solids and Fluids, John Wiley, 1999.

[23] Palermo, L. Jr., Almeida, L.P.C.P.F. \& Gonçalves, P.C., The Use of the Tangential Differential Operator in the Dual Boundary Element Equation, Structural Durability and Health Monitoring, vol. 2, Tech Science Press, pp. 123-130, 2006.

[24] Palermo, L. Jr. \& Almeida, L.P.C.P.F., On the use of the tangential differential operator in the traction boundary integral equation of the dual boundary element method for three dimensional problems. ICCES, 7(2), pp. 83-87, 2008.

[25] Palermo, L. Jr., The tangential differential operator applied to a stress boundary integral equation for plate bending including the shear deformation effect. Engineering Analysis with Boundary Elements, 36(8), pp. 1213-1225, 2012.

DOI: $10.1016 /$ j.enganabound.2012.02.010. 
[26] Gonçalves, P.C., Palermo, L. Jr. \& Proença, S.P.B., A boundary element formulation for crack analyses incorporating a cohesive zone model. International Journal of Computational Methods and Experimental Measurements, 5(3), pp. 231-240, 2017. DOI: $10.2495 / \mathrm{cmem}-\mathrm{v} 5-\mathrm{n} 3-231-240$.

[27] Gonçalves, P.C., Palermo, L. Jr. \& Proença, S.P.B., Analysis of two cohesive zone models for crack propagation in notched beams using the BEM. International Journal of Computational Methods and Experimental Measurements, 6(6), pp. 1057-1066, 2018. DOI: 10.2495/cmem-v6-n6-1057-1066.

[28] Palermo, L. Jr., Gonçalves, P.C. \& Figueiredo, L.G., A simple implementation of the dual boundary element method using the tangential differential operator for plane problems. XXXII Boundary Elements and other Reduction Methods, WIT Press: Southampton, pp. 75-84, 2010.

[29] Aliabadi, M.H., The Boundary Element Method, Applications in Solids and Structures, vol. 2, John Wiley, 2002.

[30] Telles, J.C.F., A self-adaptive co-ordinate transformation for efficient numerical evaluation of general boundary element integrals. International Journal for Numerical Methods in Engineering, 24(5), pp. 959-73, 1987. DOI: 10.1002/nme.1620240509.

[31] Bruggi, M. \& Venini, P., A numerical investigation on the size effect of fiberreinforced concrete specimens in crack propagation. Computational Mechanics, 50(1), pp. 99-117, 2012. DOI: 10.1007/s00466-011-0677-3. 